\title{
Por que precisamos de poesia sinalizada em educação bilíngue ${ }^{1}$
}

\section{Why we need signed poetry in bilingual education}

\author{
Rachel Sutton-Spence ${ }^{2}$
}

\begin{abstract}
RESUMO
Uma verdadeira educação bilíngue e bicultural para crianças surdas requer que elas aprendam a forma de arte surda de poesia em língua de sinais. Neste artigo apresento as vantagens e desvantagens de se fazer isto. Revisando a escassa literatura sobre o ensino de poesia sinalizada para crianças surdas, seja traduzida ou original, eu a relaciono ao uso de literatura em cenários de aprendizagem de L2. Reflexões de professores-poetas surdos do Reino Unido mostram que a criança surda prontamente se simpatiza com a poesia sinalizada, e com o foco linguístico adequado dos professores, isto as ajuda a desenvolver uma gama de habilidades linguísticas e a expressar suas emoções. Barreiras para isto, contudo, incluem a falta de treinamento e apreensão de professores surdos e ouvintes - mesmo quando os professores são poetas.

Palavras-chave: poesia em língua de sinais; educação bilíngue; poetas-professores surdos; aprendizagem de literatura sinalizada em L1; aprendizagem de literatura sinalizada em L2.
\end{abstract}

\begin{abstract}
A truly bilingual and bicultural education for deaf children requires them to learn about the deaf art-form of sign language poetry. In this article I outline the advantages and challenges of doing this. Reviewing the scarce literature on teaching deaf children signed poetry, whether translated or original, I relate it to use of literature in L2-learning settings. Reflections
\end{abstract}

DOI: $10.1590 / 0104-4060.37018$

1 Este trabalho foi financiado pela CAPES, como parte do programa PVE, 17881/12-9. Traduzido por Cayley Guimarães.

2 University of Bristol. Bristol, UK. Graduate School of Education, 35 Berkeley Square, BS8 1JA. 
of deaf teacher-poets from the UK show that deaf children readily relate to signed poetry, and with informed language focus from teachers it helps them develop a range of language skills, and express their emotions. Barriers to this, however, include lack of training and awareness for both deaf and hearing teachers - even when the teachers are poets.

Keywords: sign language poetry; bilingual education; deaf poet-teachers; signed literature in L1 learning; signed literature in L2 learning.

'The work of Deaf poets serves as a prism through which Deaf people can know themselves better and through which the rest of the world can see life in a new light." (Clark, 2009, 7)

\section{Introdução}

Línguas de sinais têm cada vez mais sido aceitas como meio (L1) para instrução de crianças surdas, começando nos anos 1970, e ganhando força especialmente a partir dos anos 1990, seguindo o trabalho seminal de Johnson, Liddell e Erting, "Unlocking the curriculum", de 1989. Lange et al. (2013) apresentam evidências de vantagens cognitivas da educação bilíngue da fala em língua de sinais e seus benefícios para as habilidades de leitura das crianças surdas. A língua de sinais é também amplamente ensinada como uma matéria L2 para (em sua maioria) adultos (veja, por exemplo, Myers e Fernandes, 2010, para a American Sign Language [Língua de Sinais dos Estados Unidos] - ASL, ou Sutton-Spence e Woll, 2011, para a British Sign Language [Língua de Sinais Britânica] - BSL), e estes também podem se beneficiar da exposição à poesia em língua de sinais, mas isto não será explorado neste artigo.

As pesquisas geralmente focam nos resultados linguísticos mensuráveis da educação bilíngue, mas a aprendizagem da língua é mais do que simplesmente a aquisição de competência na L1 ou L2. Como Paran (2008, p. 14) observa, a literatura na aprendizagem de língua também é importante "porque língua é aprendida por seres humanos, e o interesse e amor à literatura por suas várias qualidades é uma característica humana". Portanto, pergunto como um aspecto do ensino em um ambiente bilíngue - usando poesia sinalizada - pode impactar professores, alunos e suas experiências de aprendizagem?

Embora haja relativamente poucas salas de aula bilíngues para crianças surdas (dado que a maioria das crianças surdas são atualmente educadas no 
ambiente dominante na maioria dos países), o princípio geral de ambientes de salas de aula bilíngues é aceito, e, portanto, podemos começar a explorar com mais profundidade a diversidade de formas de línguas de sinais que devem ser introduzidas na sala de aula. Considero aqui o papel que a poesia sinalizada como um gênero criativo de língua de sinais pode atuar nos ambientes educacionais bilíngues. Pesquisadores brasileiros consideram esta hipótese, especialmente em relação a trazer a Cultura Surda e literatura para salas de aula bilíngues (e.g. STROBEL, 2008; SANTOS et al., 2011; MOURÃO, 2011). Irei focar na importante conexão entre literatura, língua, aprendizagem de língua e o aprendiz de língua. Proponho que a criança deve ver a poesia sinalizada como parte de seu desenvolvimento de L1 nas escolas na medida em que isto impacta as suas habilidades linguísticas e o seu próprio senso de individualidade e identidade. Espero que as questões levantadas inspirem educadores que trabalham com língua de sinais em sala de aula a adotarem poesia sinalizada como parte do currículo e, talvez, encorajem aqueles que ainda precisam de convencimento dos benefícios do bilinguismo sinalizado para que explorem o seu potencial. Skliar e Quadros (2004, p. 369) observam:

[...] a educação bilíngue deve ser apenas o ponto de partida da educação de Surdos, uma vez que é o começo de políticas sobre identidade Surda, conhecimento e poder Surdo e ouvinte, Movimentos de resistência Surda, ideologia, discursos hegemônicos, papéis da escola e políticas públicas.

A poesia de língua de sinais é inseparavelmente unida ao mesmo fenômeno, constituindo elementos da identidade Surda, conhecimento e poder Surdo e ouvinte, movimentos de resistência Surda, ideologias e discursos hegemônicos, que foram todos percebidos como essenciais em vários poemas sinalizados (e.g. MILES, 1998; QUADROS; SUTTON-SPENCE, 2006; SUTTON-SPENCE, 2006; CHRISTIE; WILKINS, 2007). Portanto, podemos ver que poesia sinalizada, educação bilíngue e educação do Surdo são fortemente conectadas e todos que desejarem se engajar no "Mundo Surdo" (LANE; HOFFMEISTER; BAHAN, 1996) precisam se conscientizar destes temas.

Todos os estudantes podem assistir poesia sinalizada simplesmente para diversão, mas eles também podem estudá-la como uma forma de arte linguística que pode desenvolver percepção e amor à língua e entendimento de palavras (sinalizadas ou escritas) e a forma da língua. Paran (2008) descreve os efeitos da literatura na aprendizagem de língua, mostrando como aulas que se utilizam da literatura podem ter um foco voltado à aprendizagem de língua, um foco voltado 
à aprendizagem da literatura, ou ambos. Mostrarei como um foco voltado à língua pode resultar em uma aprendizagem mais efetiva e prazerosa. Com um foco mais literário, os temas e significados contidos na poesia podem também aumentar o entendimento de emoções e ideias complexas, tais como metáforas, especialmente para estudantes mais jovens. O estudo de poesia sinalizada abre a mente dos estudantes para o letramento de poesia, de maneira que eles aprendem as convenções dentro das quais a poesia é entendida - seja escrita ou sinalizada. Uma vez tendo apreciado e estudado poemas sinalizados dos outros, os estudantes devem ser encorajados a recitar e criar as suas próprias poesias sinalizadas, expressando as suas emoções, desenvolvendo confiança em interações sociais e linguísticas, orgulhando-se da expressão própria e desenvolvendo as suas próprias habilidades em língua de sinais.

Neste artigo considero a poesia executada como uma composição original em língua de sinais, ou uma tradução para língua de sinais de um poema escrito. Usarei o termo "poesia sinalizada" para me referir a qualquer poesia em língua de sinais - seja traduzida ou escrita em língua de sinais.

As observações e propostas aqui apresentadas se baseiam em trabalhos de profissionais e acadêmicos (e.g. PARAN, 2008, em sua revisão abrangente da efetividade da literatura no ensino e aprendizagem de língua estrangeira). As pesquisas que mostram resultados sobre a experiência de professores com poesia sinalizada em sala de aula (tendo sido encontradas bem poucas) são complementadas com relatos reflexivos de três poetas surdos sinalizadores e professores. Embora estes depoentes morem no Reino Unido, espero que seus relatos ecoem para os leitores no Brasil e em outros países. Rosa e Klein (2011), em seu trabalho inovador, perguntaram a professores surdos a respeito de suas opiniões sobre a literatura sinalizada disponível para crianças surdas no Brasil, focando-se na língua usada, nos aspectos técnicos e de execução das composições e nos aspectos culturais representados. Seguirei esta abordagem, considerando as reflexões dos poetas surdos e professores sobre o uso de poesia sinalizada para o ensino.

\section{Observações e depoimentos}

Paran (2008, p. 17) observa que grande parte das evidências significativas a respeito do uso bem-sucedido de literatura no ensino de língua vem de observações de professores, e que "interações em sala de aula podem ser exploradas através de depoimentos de um profissional refletindo sobre o que ele faz em sala 
de aula". Uma pesquisa qualitativa neste sentido em Estudos Surdos foca em dar "voz" às pessoas que raramente são notadas por pesquisadores e criadores de políticas - neste caso, dar voz aos poetas surdos e professores.

Paul Scott, Richard Carter e John Wilson são poetas surdos Britânicos bem conhecidos e amplamente respeitados que compõem e executam poesia em língua de sinais, e os três já ensinaram poesia sinalizada para crianças surdas. Paul e Richard já trabalharam em escolas bilíngues com crianças surdas. Tive o privilégio de estar presente às entrevistas individuais, seminários e discussões em grupos pequenos, que ocorreram entre 2006 e 2013, em que eles explicaram e refletiram sobre seu trabalho e filosofias por trás de sua poesia e ensino. Em todos os casos, os eventos foram filmados e transcritos e os poetas deram permissão para que o material fosse analisado e apresentado como parte de pesquisa de literatura em língua de sinais. Há uma grande quantidade de trabalho qualitativo que investiga a efetividade de abordagens bilíngues na educação de surdos (HERMANS, 2007, e HUMPHRIES; MACDOUGALL, 2000, são dois de muitos), reportando "fatos" de conquistas educacionais. Para complementar este trabalho amplo, generalizado e objetivo, tenho como finalidade mostrar as "vozes" humanas - ou seja, o máximo da presença sinalizada quanto possível de pessoas surdas que revelem suas experiências e pensamentos (COLEMAN; BRIGGS, 2002). Os comentários destas vozes podem ressoar e apresentar uma realidade reconhecível para o leitor, alguns podem ser generalizáveis e transferíveis, mas a variedade de opiniões e experiências reflete a diversidade e complexidade do uso da poesia sinalizada em situações de sala de aula.

\section{Por que ensinar poesia à criança surda?}

Em 1979, Robert Panara, um poeta Americano surdo e professor, advogava o ensino de poesia escrita para a criança surda através da intermediação da língua de sinais. Ele escreveu que ensinar poesia

[...] ajuda a estimular criatividade e expressão pessoal, e encoraja o desenvolvimento das faculdades intelectuais do estudante - imaginação, pensamento e interpretação [...]. Assim como na exposição às artes dramáticas ou à dança, faz o estudante reagir emocionalmente e sensitivamente à arte de expressão [...]. Através da linguagem da poesia os estudantes podem aprender a perceber como o lugar comum é feito parecer incomum, 
como palavras antigas podem ser expressas com frescor, originalidade e beleza (PANARA, 1979, p. 825).

Esta linha de raciocínio pode também ser aplicada ao ensino de poesia original em língua de sinais. Os benefícios do ensino de poesia à criança surda são tão grandes quanto o são para o ensino de crianças ouvintes. De fato, a poesia sinalizada pode ser mais importante para a criança surda se der a ela acesso estendido ao uso criativo de língua de sinais, o que elas não teriam de outra forma. Se o professor é um poeta isto pode prover uma dimensão extra à aprendizagem, mas todas as aulas podem explorar poesia, seja ela originariamente composta na língua escrita ou na língua de sinais.

\section{Poesia sinalizada e escrita}

Não há dúvidas de que alguns surdos gostam de ler poesia escrita. Este é particularmente o caso de surdos pós-linguísticos (CLARK, 2009), mas há outros leitores surdos habilidosos que também apreciam os desafios linguísticos da leitura, para quem a poesia escrita pode ser agradável (KELSTONE, 2012). Contudo, muitas pessoas surdas encontram dificuldades para entender ou apreciar a poesia escrita devido às dificuldades em entender a língua ou as referências culturais usadas porque elas não são familiarizadas com as convenções necessárias (SHETLEY, 1993; VALLI; GRAYBILL apud NATHAN LERNER; FEIGEL, 2009). Como Paul Scott comentou:

Eu pego [um livro de poesia] da prateleira e começo a ler e não entendo. Talvez seja lindo, com belas palavras, todas musicalmente arranjadas na página. Eu leio "bla, bla, bla" e as pessoas ouvintes irão ver as metáforas e a linguagem figurativa e assim por diante, mas eu olho e não faz sentido para mim. As pessoas ouvintes entendem e a pessoa surda não.

John Wilson, considerando suas primeiras experiências como poeta, diz:

Minha escola me ensinou poesia - tudo sobre rima, denotação, conotação, verso - e eu não tinha ideia do que tudo significava. Naquela época meu 
Inglês era muito limitado. Nós tínhamos que escrever nossos próprios poemas. Era uma luta árdua. Eu odiava. Eu fugia.

Isto não parece ter mudado muito desde os tempos de escola do John, como vemos na pesquisa de Arensen e Kerschmer (2010), que dizem que seis estudantes em suas aulas de poesia não tinham experiência com ela, ou a achavam "chata". Richard Carter descreve um workshop que ele deu em uma escola de surdos:

Eles me pediram para falar sobre poesia Inglesa porque o professor os havia feito ler poesia Inglesa repetidamente e eles não entendiam. "Nós não gostamos de poesia Inglesa". Então eu disse: "Eu não sei com o que a poesia Inglesa se parece. Mostre-me o seu livro". [...] Eles me pediram para explicar e eu disse: "Eu também não entendo isto". O professor dos surdos me disse que eles não entendem o que poesia significa.

Há bastante evidência de que a língua de sinais auxilia no desenvolvimento da língua escrita (JOHNSON; LIDDELL; ERTING, 1989), o que torna desnecessário repetir os argumentos aqui. É claro, também, conforme descreve o trabalho pioneiro de poetas-professores como Robert Panara, nos Estados Unidos nos anos 1940, que, embora os estudantes usualmente respondam mais intensamente à poesia em língua de sinais, ver a poesia escrita traduzida para a língua de sinais e discuti-la em língua de sinais ensina os estudantes sobre letramento de poesia em geral. Isto os capacita a abordar poesia de maneira crítica e a explorar as dificuldades culturais, linguísticas e atitudinais que podem criar barreiras à sua apreciação (SHETLEY, 1993). Então, eles começam a realmente entender o significado dos poemas e das palavras que os criam (PANARA, 1979; ARENSON; KRETSCHMER, 2010). Como Lang (2007) observou, sinalizar a respeito de poesia escrita leva sua mensagem aos estudantes. Paran (2008) observa que a literatura em uma aula de língua é geralmente discutida na L1 dos estudantes. Para os estudantes surdos para quem a língua de sinais é a sua L1, esta é a perfeita oportunidade para encorajar uma discussão sinalizada. Palavras em poesia são palavras "bonitas" somente para os estudantes que sabem como usá-las. Lang (2007, p. 63) cita Bernard Bragg, um poeta Americano surdo, descrevendo os efeitos do ensino de poesia escrita que Panara faz por meio de língua de sinais: 
Ele nos ensinou algo a respeito do Inglês, até então uma segunda língua estranha para nós sinalizadores nativos, ao interpretar em sinais não apenas o sentido geral, mas cada palavra individual nas linhas da poesia [...] de maneira a finalmente fazer com que elas se tornassem vivas para nós.

Professores devem se conscientizar da fragilidade da recém-adquirida confidência poética dos estudantes, contudo, e usá-la com cautela. Paul Scott descreve um incidente em que um professor de Inglês tenta persuadir os estudantes a traduzir o trabalho criativo deles em língua de sinais para o Inglês, com resultados desencorajadores:

A professora chegou e estava fascinada [pela sinalização criativa dos estudantes] [...] Ela achou perfeito porque queria que eles escrevessem estas histórias nas aulas de Inglês, de maneira que ela pudesse ensinálos como escrever em bom Inglês, mas as crianças simplesmente não estavam motivadas. Então por que eles pararam? Eles sinalizaram de maneira correta para mim e, na aula de Inglês, a professora os elogiou por sinalizarem tão bem e disse: "Agora nós queremos que vocês as escrevam”. A força/obrigação/pressão/opressão [aqui o sinal da BSL carrega todos estes significados] para com os estudantes para polir o Inglês desmotivou as crianças. Quando elas voltaram para a minha classe já não queriam fazer (sinalização criativa) mais porque elas tinham acabado de voltar da aula de Inglês. Era frustrante.

\section{Benefícios de se ver poesia sinalizada}

Ver a poesia em língua de sinais abre uma dimensão completamente nova em que a beleza e os desafios da forma poética ainda estão presentes, mas as barreiras da língua são removidas. $\mathrm{O}$ impacto da exposição à poesia sinalizada não pode ser subestimado. John Wilson diz:

Eu me lembro de ver pela primeira vez um poema longo em BSL quando eu era uma criança. [Um amigo da escola de uma família surda] sinalizou um poema simples sobre uma árvore perto de um rio, balançando ao vento. Ver esta sinalização teve um impacto realmente forte em mim. Eu ri por anos depois. Eu não estava rindo dela, mas sim do prazer de ver o poema 
dela. Era como se fosse um tapa na cara - era a primeira vez que eu tinha visto algo tão claramente. Eu me senti como se estivesse dentro da cena. Eu me tornei parte dela. Eu estava dentro da cena com a grande árvore lá e o rio aos meus pés. Estava tudo na minha cabeça. Era incrível. Eu havia crescido em um nevoeiro de informação. Alguns pequenos pedaços de informação penetravam este nevoeiro, mas quando eu vi o poema o nevoeiro desapareceu totalmente e eu pude ver tudo tão claramente.

John continua explicando que "pessoas surdas podem ter acesso à poesia através da sinalização e ela pode mostrar ideias realmente poderosas. Ela pode te dar [literalmente: você pode receber] emoções muito fortes - felicidade, tristeza, raiva". A poesia escrita não o havia dado isto antes dele entender poesia sinalizada.

Poesia sinalizada pode também ajudar a unir crianças surdas de diferentes origens linguísticas. Em um ambiente educacional que pode ter espaços diferenciados para suas práticas de língua, isto é importante porque fortalece o senso de identidade surda para todas as crianças. Richard Carter dá um exemplo disso quando discute um projeto de poesia no qual ele estava envolvido:

Eram aproximadamente 20 estudantes surdos - 14, 15 e 16 anos de idade. Alguns eram bastante oralizados e alguns eram sinalizadores fluentes. Era muito variado. Era em escola regular [...]. As crianças oralizadas não sinalizavam muito mas elas entendiam poesia inglesa escrita, porém não entendiam poesia em BSL. Os demais entendiam poesia sinalizada mas não entendiam poesia inglesa escrita. Eram opostos. Eu precisava pensar sobre o que aconteceria aos dois grupos se eu desse a eles o mesmo poema. Interessantemente, eles todos entenderam. Quando estavam brincando, as crianças oralizadas sinalizavam também, mas na escola elas apenas oralizavam. [...] Então eu dei a cada um deles um pedaço de fruta [para inspiração] e eles criaram algo poético para si mesmos. Mesmo as crianças oralizadas criaram coisas bonitas. Então elas apreenderam a ideia de poesia em BSL.

\section{Melhorando as habilidades linguísticas de sinalizadores em L1}

A poesia é particularmente adequada para a aprendizagem de língua porque os estudantes devem entender a forma para entender o poema. Ela chama nossa atenção para a língua e suas regras (SUTTON-SPENCE, 2001). Dado 
que a língua usada em poesia sinalizada geralmente desvia-se da sinalização cotidiana, a poesia chama a atenção para as regras da língua de sinais "correta" ao desrespeitá-las (LEECH, 1969). As crianças surdas precisam desenvolver um entendimento e uma apreciação explícita da língua que estão usando, e a poesia pode ser uma maneira de ajudá-las a fazer isto. Para que isso ocorra os professores precisam se debruçar sobre a língua no poema, para que o estudante entenda o objetivo da lição (SCOTT, 2010). Frequentemente, as aulas de literatura e de língua são distribuídas em uma tabela de tempo e na mente do estudante, mas os professores podem ajudar os estudantes a apreciar que a poesia pode ser uma oportunidade para aprender sobre a língua tanto quanto sobre a literatura.

Lang (2007, p. 61-62) cita Bernard Bragg novamente falando da sinalização poética de Robert Panara:

[...] em contraste com os sinais cortados, abruptos e geralmente caseiros que usávamos entre nós, os seus sinais eram um milagre de vivacidade e eloquência [...] nós nunca havíamos percebido que isto, nossa língua nativa, podia ser um veículo tão poderoso para expressar os sentimentos mais ricos e sutis e passar nuances de significados tão sofisticados quanto os mais articulados usados pelos falantes e escritores ingleses.

John Wilson explicou que ao ensinar poesia sinalizada ele encoraja as crianças a irem além de seus limites de habilidades de sinalização para usar mais elementos não manuais e emoções, focando na configuração das mãos, na velocidade da sinalização e no uso de simetria e espaço. Richard Carter enfatizou a exploração do potencial de classificadores com crianças mais velhas (aí incluída a apresentação a elas de sinalização poética surreal "em que a criança pega o sol-laranja e o come") e Paul Scott encoraja as crianças a pensarem sobre tudo isto e também em relação à repetição, ao espaço de sinalização e à configuração das mãos. John Wilson mostra como a poesia pode se valer das habilidades existentes na criança surda quando ela cria poemas usando apenas uma configuração de mão:

[...] quando os professores me veem brincando com os seus pupilos eles ficam admirados com o vocabulário das crianças. Eles esperam um grau menos elevado de vocabulário e veem todos os tipos de sinais, então eles dizem: "Eu não sabia que você conhecia aquele sinal. Oh, garoto inteligente!". É tão paternalista! As crianças “arremessam” vocabulário, e rápido. 
As crianças nem sempre acham fácil desenvolver as suas habilidades expressivas de língua e os professores precisam protegê-las e fomentá-las cuidadosamente. Paul Scott explica a importância de construir o entusiasmo da criança para a sinalização criativa, e como esta sinalização criativa pode ser esmagada por professores que não entendem, ou por regras restritivas e inflexíveis de como usar a língua que impedem as crianças de explorar o seu potencial. Portanto, quando as crianças viram a sinalização criativa de Paul em um ambiente formal de sala de aula elas o questionaram: "Isto é permitido?". Quando elas aprendem que elas têm "permissão" de um adulto para brincar com a língua, as suas habilidades se desenvolvem: "Quando eu sinalizo [...] fora do espaço de sinalização, as crianças olham espantadas. 'Uau! Isto é permitido! Então nós podemos, nós temos permissão, também."”.

\section{Emoções e experiências pessoais}

Embora haja tantas definições de poesia quanto há poetas, uma opinião amplamente aceita é a de que a poesia mostra "emoções expressas em uma língua compacta", de maneira que "poesia é um recipiente de emoções" (BOUDREAU, 2009 , p. 2). É também uma maneira para os poetas descreverem as suas experiências. Boudreau $(2009$, p. 3$)$ nota que as "crianças precisam escolher e criar poesia que expresse sua própria vida pessoal" para descrever suas experiências e expressar suas emoções, e a poesia sinalizada pode ser o canal de expressão para isto. John Wilson observa:

[...] poesia sinalizada é uma maneira de expressar nossas experiências pessoais e é por isto que poesia sinalizada é uma parte importante da cultura Surda. A experiência pode ser positiva ou negativa, mas é válida. Os poetas podem mostrar isto, audiências podem ver e apreciar os poemas, pois eles são importantes. É importante incluir a celebração de nossa história e nossas experiências de opressão. Tudo isto é valioso, e é por isto que poesia sinalizada é importante.

As crianças surdas se relacionam com esta expressão da experiência pessoal na poesia em língua de sinais. Arenson e Kretschmer (2010, p. 112) relatam que estudantes surdos naturalmente respondem melhor a poemas sinalizados 
em relação a poemas escritos, durante as aulas de poesia. Quando os autores deram aos estudantes uma seleção de poemas em inglês e em ASL e pediram a eles que escolhessem um poema com o qual pudessem conectar-se com as suas experiências pessoais, todos os seis estudantes escolheram poemas em ASL ao invés dos poemas escritos em inglês. Eles descobriram posteriormente que:

As respostas dos estudantes [a um poema em ASL de Clayton Valli] indicam que elas se vincularam profundamente com a mensagem do poema. Por exemplo, quatro estudantes [...] escreveram reações ao poema que mostravam histórias pessoais ecoando no tema do poema de solidão, tédio, e no sentimento de ser ignorado, na falha de outros em se comunicar (2010, p. 113).

Isto é uma clara evidência de que os estudantes podem usar discussões de literatura para promover suas competências comunicativas de uma maneira geral (KIM, 2004).

John Wilson descobriu que várias pessoas jovens surdas se sentiam incapazes de serem críticas em relação a pessoas ouvintes que não utilizavam a linguagem de sinais, geralmente aquelas em posição de autoridade sobre elas. Ele obteve sucesso encorajando adolescentes Surdos a colocar seus sentimentos mais fortes em poemas em língua de sinais na liberdade de um ambiente totalmente sinalizado em que eles se sentissem seguros para se expressar sem medo de punição. Permitir que estudantes surdos criem poesia em língua de sinais também altera a balança de poder. Quando John organizava apresentações de trabalho dos adolescentes surdos ele enfatizava que "eram todos surdos - não havia voz. A interpretação era um problema dos ouvintes. Os ouvintes não conheciam os sinais, então restava a eles sentar e sorrir estupidamente mesmo para poemas raivosos".

\section{A importância de poetas sinalizadores como professores}

Professores que não são poetas podem ensinar sobre poesia usando vídeos de apresentações (ROSA; KLEIN, 2011; ARENSON; KRETSCHMER, 2010), mas se um professor é um poeta e se um poeta é um professor os estudantes podem desenvolver uma melhor compreensão da poesia. A Antologia de Poesia 
Surda Americana de John Lee Clark (2009) se refere a vários poetas surdos que ensinam em escolas de surdos, faculdades e universidades, a partir do século XIX, mostrando o papel crucial que eles desempenham no suporte e promoção da poesia sinalizada e poetas sinalizadores. Muitos poetas surdos hoje já trabalharam em escolas de surdos em algum momento ou conduziram workshops de poesia com crianças surdas, adultos surdos e adultos ouvintes que aprendiam a língua de sinais. Campello (2007) nota como professores com o dom de sinalização altamente visual podem ser um grande recurso para a educação bilíngue.

Poetas-professores são capazes de explicar poemas em língua de sinais ou traduzir poemas para a língua de sinais para fornecer aos estudantes o significado do poema. Contudo, o poeta-professor precisa de treinamento em letramento poético. De fato, há uma necessidade de capacitar todos os professores a utilizar poesia sinalizada formalmente de maneira culturalmente apropriada, que se adapte à cultura surda. Richard Carter explica:

Eu particularmente aprecio poesia para crianças. Eu adoro sinalizar/ oferecer/contar a poesia [o sinal em BSL carrega todos estes significados]. É bom para elas porque significa que no futuro elas podem produzir suas próprias poesias e se tornarem poetas porque eu as influenciei continuamente, porque ninguém me influenciou. Eu estava sozinho. Ninguém me explicou. Eu estava sozinho e não sabia das coisas.

E Paul Scott relembra do tempo em que ele trabalhou com crianças surdas em sua sala de aula para que elas pudessem entrar em uma competição de poesia sinalizada. Ele e as crianças se basearem em habilidades existentes e ganharam, mas uma consciência explícita estava faltando:

As crianças todas tinham habilidades inatas e eu tinha um bom relacionamento de ensino com elas. Então os poemas tinham que ter a mesma configuração de mãos, repetição, palavras, clareza, sentimentos - por exemplo, o sol, sensação de calor ou frio -, mudança de sinais e assim por diante [...] mas [...] eu sinto que eu sabia como usar a poesia, mas não como ensiná-la. Não estou seguro - eu precisava de alguém que a ensinasse, que soubesse as regras. Quando eu estava fazendo poemas eu não sabia estas coisas. 


\section{Livros, poesia sinalizada e poesia em língua de sinais}

Há evidências de que a poesia sinalizada original pode ajudar estudantes a apreciar e se engajar com a poesia escrita (ARENSON; KERSCHMER, 2010; LANG, 2007), mas é também o caso de a poesia sinalizada ser uma tradução altamente visual de palavras escritas, que pode gerar um "ponto de partida" para a apreciação e criação de poesia original em língua de sinais.

John Wilson cita:

A jornada de Dorothy [Miles - uma surda poeta pioneira em língua de sinais] de poesia escrita para poesia em BSL é realmente a história da poesia em língua de sinais na Grã-Bretanha. Ela combinou as duas formas. Seu primeiro workshop foi ensinado em Inglês [...] Este curso foi um trabalho árduo para nós todos que discutíamos, debatíamos e refinávamos as coisas e lentamente trabalhávamos em direção à poesia em BSL. Mas eu me senti triste por ela ter morrido justamente quando tinha chegado lá [...] agora podemos focar inteiramente em BSL. As pessoas surdas são livres para se expressarem sem serem atrapalhadas pelo Inglês. Aquela nuvem de Inglês sobre a qual falei anteriormente é removida.

Um haiku sinalizado também pode vir de imagens visuais (e.g. o poema haiku de Paul Scott intitulado Turkey foi inspirado em um simples cartão de fotografia) ou ser baseado em uma imagem visual criada por um haiku escrito (e.g. o haiku de Jack Cain "an empty elevator/opens/closes" inspirou o haiku de John Wilson de 2010 intitulado Lift). Em outro exemplo de poesia sinalizada original inspirada por poesia escrita, o poema em BSL de John Wilson intitulado Two Communities é derivado do poema Inglês Explosion de Philip Larkin. O poema de John inclui personagens surdos, estilo de vida dos surdos e cultura surda e não segue os padrões da língua Inglesa, mas foi inspirado por um poema escrito. As crianças devem ser encorajadas a participarem destas atividades para o desenvolvimento de habilidades de língua e poesia que se baseiam nos sinais, livros e palavra escrita.

\section{Conclusões}

Eu considerei as visões de ouvintes adultos que apreciam os benefícios da poesia sinalizada e as de surdos adultos que, olhando em retrospectiva para 
sua infância, podem imaginar como gostariam de ter tido acesso à poesia sinalizada e podem ver os benefícios para as crianças de hoje. O próximo passo importante será descobrir a respeito das crianças de hoje sobre como elas vivem a experiência e apreciam a poesia sinalizada nas escolas.

Até lá, contudo, as reflexões destes três professores-poetas mostram os benefícios de se introduzir poesia sinalizada em salas de aula bilíngue. Quando os professores são suficientemente bem treinados e tendo recursos disponíveis, a poesia sinalizada pode evitar algumas barreiras geralmente criadas quando as pessoas surdas veem a poesia escrita sem as habilidades literárias para apreciá-la, fazendo com que aumentem as chances de se apreciar poesia escrita e sinalizada. Ela pode unir crianças surdas de diferentes origens linguísticas, provendo a elas oportunidades de expressar emoções, aprender a respeito da cultura surda e do mundo ouvinte e desenvolver suas habilidades linguísticas explorando o potencial da língua.

Tendo em vista que o argumento de poetas surdos e professores para o uso de poesia sinalizada em sala de aula é tão forte, devem-se questionar as barreiras contra o seu uso. A maior destas barreiras se encontra na falta de treinamento dos professores surdos e ouvintes em poesia em língua de sinais. Adicionalmente, os professores podem não ter acesso a bons recursos ou podem argumentar que não há tempo suficiente em sala de aula para trabalhar com a poesia, uma vez que não está no currículo. Precisamos aumentar o treinamento e prover mais recursos. Talvez, contudo, o ponto principal seja a falta de percepção da importância da poesia e da poesia sinalizada, e, neste caso, eu espero que este artigo possa aumentar um pouco mais esta percepção.

\section{REFERÊNCIAS}

ARENSON, R.; KRETSCHMER, R. Teaching poetry: a descriptive case study of a poetry unit in a classroom of urban deaf adolescents. American Annals of the Deaf, 155, 2, p. 110-117, 2010.

BOUDREAU, K. Slam Poetry and Cultural Experience for Children. Forum on Public Policy: A Journal of the Oxford Round Table. 2009. Disponível em: <http://www.questia. com/library/journal/1G1-216682605>. Acesso em: jan. 2014.

CAMPELLO, A. Pedagogia Visual/Sinal na Educação dos Surdos. In: QUADROS, R. Muller de; PERLIN, G. (Eds.). Estudos Surdos II. Petrópolis, RJ: Arara Azul, 2007. p. $100-131$. 
CHRISTIE, K.; WILKINS, D. Themes and Symbols in ASL Poetry: Resistance, Affirmation, and Liberation. Deaf Worlds, v. 22, n. 3, p. 1-49, 2007. Disponível em: $<$ https://ritdml.rit.edu/handle/1850/14261 $>$. Acesso em: 24/07/2014.

CLARK, J. (Ed). Deaf American Poetry. Washington DC: Gallaudet University Press, 2009.

HERMANS, D.; KNOORS, H.; ORMEL, E.; VERHOEVEN, L. The relationship between the reading and signing skills of deaf children in bilingual education programs. Journal of Deaf Studies and Deaf Education, v. 13, p. 518-530, 2008.

HUMPHRIES, T.; MACDOUGALL, F. 'Chaining' and other links: Making connections between American Sign Language and English in Two Types of School Settings. Visual Anthropology Review, v. 15, n. 2, p. 84-94, 1999/2000.

JOHNSON, R.; LIDDELL, S.; ERTING, C. Unlocking the curriculum: Principles for achieving access in deaf education. Washington, D.C.: Gallaudet University, 1989.

KELSTONE, A. Understanding deaf readers: an interpretative phenomenological analysis. Unpublished education doctoral dissertation, Northeastern University, USA, 2012.

KIM, M. Literature discussions in adult L2 learning. Language and Education, v. 18, n. 2, p. 145-166, 2004.

LANE, H.; HOFFMEISTER, R.; BAHAN, B. A Journey into the DEAF-WORLD. San Diego, C.A.: Dawn Sign Press, 1996.

LANG, H. Teaching from the Heart and Soul: The Robert F. Panara Story. Washington DC: Gallaudet University Press, 2007.

LANGE, C.; LANE-OUTLAW, S.; LANGE, W.; SHERWOOD, D. American Sign Language/English Bilingual Model: A Longitudinal Study of Academic Growth. Journal of Deaf Studies and Deaf Education, v. 18, n. 4, p. 532-544, 2013.

LEECH, G. A linguistic guide to English poetry. London: Longman, 1969.

MILES, D. Bright Memory: The Poetry of Dorothy Miles. Feltham, Middlesex: British Deaf History Society Publications, 1998.

MOURÃO, C. Literatura Surda: produções culturais de surdos em língua de sinais. In: KARNOPP, L.; KLEIN, M.; LUNARDI-LAZZARIN, M. (Eds.). Cultura Surda na contemporaneidade. Canoas RS: Editora ULBRA, 2011. p. 71-90.

MYERS, S. S.; FERNANDES, J. K. Deaf Studies: A Critique of the Predominant U.S. Theoretical Direction. Journal of Deaf Studies and Deaf Education, v. 15, n. 1, p. 3049, 2010.

NATHAN LERNER, M.; FEIGEL, D. The Heart of the Hydrogen Jukebox. New York: Rochester Institute of Technology, 2009. DVD. 
NOVAK, J. Performing the Poet, Reading (to) the Audience: Some Thoughts on Live Poetry as Literary Communication. Journal of Literary Theory, v. 6, n. 2, p. 358-382, 2012. DOI 10.1515.

PANARA, R. On teaching poetry to the Deaf(Or: Let the Student be the Poem!). American Annals of the Deaf, p. 825-828, 1979.

PARAN, A. The role of literature in instructed foreign language learning and teaching: An evidence-based survey. Language Teaching, v. 41, n. 4, p. 465-496, 2008.

QUADROS, R.; SUTTON-SPENCE, R. Poesia em Língua de Sinais: Traços da identidade surda. In: QUADROS, R. Muller de (Ed.). Estudos Surdos 1. Petrópolis, Rio de Janeiro: Editora Azul, 2006. p. 110-165.

ROSA, F.; KLEIN, M. O que sinalizam os professores surdos sobre literatura surda em livros digitais. In: KARNOPP, L.; KLEIN, M.; LUNARDI-LAZZARIN, M. (Eds.). Cultura Surda na contemporaneidade. Canoas RS: Editora ULBRA, 2011. p. 91-112.

SANTOS, A.; DA SILVA, B.; CARDOSO, R.; MORAES, V. Diferentes usos da cultura surda na literatura: a língua de sinais atravessada por marcas culturais e ressignificada nos processos de inclusão. In: KARNOPP, L.; KLEIN, M.; LUNARDI-LAZZARIN, M. (Eds.). Cultura Surda na contemporaneidade. Canoas RS: Editora ULBRA, 2011. p. 41-54.

SCOTT, P. Do Deaf children eat deaf carrot? In: MATHUR, G.; NAPOLI, D. Jo (Eds.). Deaf around the World: the impact of language. Oxford: Oxford University Press, 2010. p. 359-366.

SCOTT, P. BSL haiku poem Turkey (2010). Disponível em: <www.bristol.ac.uk/bslpoetryanthology>. Acesso em: 17/07/2014.

SHETLEY, V. After the Death of Poetry: Poet and Audience in Contemporary America. Durham NC: Duke University Press, 1993.

SKLIAR, C.; QUADROS, R. Bilingual Deaf Education in the South of Brazil. International Journal of Bilingual Education and Bilingualism, v. 7, n. 5, p. 368-380, 2004.

SUTTON-SPENCE, R. Phonological 'deviance' in British Sign Language poetry. Sign Language Studies, v. 2, n. 1, p. 62-83, 2001.

SUTTON-SPENCE, R. Images of Deaf Culture and Identity in Sign Language Poetry. In: QUADROS, R. M. de (Ed.). Sign Languages: spinning and unravelling the past, present and future. $9^{\circ}$ Theoretical Issues in Sign Language Research Conference, Florianópolis, Brasil, December 2006. Petrópolis, Rio de Janeiro: Editora Arara Azul, 2006.

SUTTON-SPENCE, R.; WOLL, B. Applied linguistics and sign languages. In: SIMPSON, J. (Ed.). Routledge Handbook of Applied Linguistics. Abingdon: Routledge. 2011. p. 359-372. 
WILSON, J. BSL haiku poem Lift (2010). Disponível em: <www.bristol.ac.uk/bslpoetryanthology>. Acesso em: 17/07/2014.

Texto recebido em $1^{\circ}$ de julho de 2014. Texto aprovado em 07 de agosto de 2014. 